OPEN ACCESS

Edited by:

Alessandra Durazzo,

Council for Agricultural and

Economics Research, Italy

Reviewed by:

Ren-You Gan,

Shanghai Jiao Tong University, China

Muhittin Kulak,

Kilis 7 Arallk University, Turkey

*Correspondence:

H. P. Vasantha Rupasinghe

vrupasinghe@dal.ca

Specialty section:

This article was submitted to

Nutrition and Food Science

Technology,

a section of the journal

Frontiers in Nutrition

Received: 13 January 2019

Accepted: 08 April 2019

Published: 25 April 2019

Citation:

Sekhon-Loodu S and

Rupasinghe HPV (2019) Evaluation of

Antioxidant, Antidiabetic and

Antiobesity Potential of Selected

Traditional Medicinal Plants.

Front. Nutr. 6:53.

doi: 10.3389/fnut.2019.00053

\section{Evaluation of Antioxidant, Antidiabetic and Antiobesity Potential of Selected Traditional Medicinal Plants}

\author{
Satvir Sekhon-Loodu and H. P. Vasantha Rupasinghe* \\ Department of Plant, Food, and Environmental Sciences, Faculty of Agriculture, Dalhousie University, Truro, NS, Canada
}

This study evaluated potential antidiabetic and antiobesity properties in vitro of selected medicinal plants. The hot water (WE) and ethanol extracts (EE) of sweet gale (Myrica gale L.), roseroot (Rhodiola rosea L.), sheep sorrel (Rumex acetosa L.), stinging nettles (Utrica dioica L.) and dandelion (Taraxacum officinale L.) were tested for total antioxidant capacity using ferric reducing antioxidant power (FRAP) and DPPH• scavenging capacity assays, followed by $\alpha$-amylase, $\alpha$-glucosidase and formation of advanced glycation end products (AGE) inhibition assays in vitro. Myrica gale EE had the highest total phenolic content (12.4 mmol GAE/L), FRAP value (17.4 mmol TE/L) and $\mathrm{DPPH}^{\bullet}$ scavenging activity $\left(\mathrm{IC}_{50}=\right.$ $3.28 \mathrm{mg} / \mathrm{L})$. Similarly, Myrica gale also exhibited significantly lower $\mathrm{IC}_{50}$ values for the percentage inhibition of $\alpha$-amylase $\left(\mathrm{IC}_{50}=62.65 \mathrm{mg} / \mathrm{L}\right)$ and $\alpha$-glucosidase $\left(\mathrm{IC}_{50}=27.20\right.$ $\mathrm{mg} / \mathrm{L})$ compared to acarbose $\left(\mathrm{IC}_{50}=91.71 \mathrm{mg} / \mathrm{L} ; \mathrm{IC}_{50}=89.50 \mathrm{mg} / \mathrm{L}\right.$, respectively $)$ $(p \leq 0.05)$. The 3T3-L1 preadipocyte study also revealed that Myrica gale EE $(54.8 \%)$ and stinging nettles (62.2\% EE; 63.2\% WE) significantly inhibited the adipogenesis in adipocytes in vitro $(0 \leq 0.05)$. Polyphenols present in these medicinal plants have the potential to use in managing type 2 diabetes and obesity.

Keywords: phytochemicals, antioxidants, polyphenols, diabetes, amylase, glucosidase, obesity

\section{INTRODUCTION}

Type 2 diabetes (T2D), characterized by hyperglycemia and abnormal carbohydrate metabolism, is a leading cause of morbidity and mortality worldwide and a major economic burden (1). According to the International Diabetes Federation, about 382 million people had diabetes in the year 2013, and the numbers are expected to get double by 2035 (2). These increased numbers of diabetes patients are mainly (>95\%) T2D which is developed due to insulin resistance and pancreatic $\beta$-cell dysfunction, leading to hyperglycemia (3). The insulin resistance and pancreatic $\beta$-cell apoptosis can be traced back to obesity and also provide the link between T2D and obesity (4). The postprandial blood glucose levels have been found to play an important role in the onset and developing complications of T2D (5). One of the therapeutic strategies for managing postprandial hyperglycemia involves the inhibition of $\alpha$-amylase and $\alpha$-glucosidase (6). The synthetic drugs such as acarbose and miglitol have strong inhibitory action against $\alpha$-amylase and $\alpha$-glucosidase; however, they may result in abdominal distention, flatulence, vomiting, and diarrhea (7). The hyperglycemia can also result in the excessive non-enzymatic glycation of proteins and formation of advanced glycation end products (AGE). The glycation modifications can further 
deteriorate the pathology of diabetes by contributing to nephropathy, cataracts, vasculopathy, and atherosclerosis (8).

A number of studies and reviews have reported that phytochemicals such as phenolics offer potential therapeutic benefits in alleviating diabetes and obesity complications and inhibitory effects against $\alpha$-amylase and $\alpha$-glucosidase (9-13). A safer alternative for management of obesity and T2D are medicinal plants which help to maintain low blood glucose and prevent high blood pressure, as well as boost body antioxidant system and insulin regulation (14). Like many other metabolic disorders, T2D is also linked to obesity (15). Infusions and decoctions of traditional medicinal plants have been used for centuries to treat various health ailments including type 2 diabetes and obesity-related metabolic disorders (16). The water infusion prepared from wild raspberry (Rubus idaeus L.) stem exhibited the inhibition of $\alpha$-amylase, $\alpha$-glucosidase activities and anti-AGE activity (17). Dandelion (Taraxacum officinale L.) has been used in traditional cancer medicines due to its hydroxycinnamic acid derivatives and flavonoid glycosides content (18). The plants containing antioxidant compounds can protect $\beta$-cells from reactive oxygen species (ROS) and therefore, can prevent diabetes induced by ROS (14). Therefore, it is pertinent to explore the traditional medicinal plants, which can be utilized for lowering blood glucose levels and also obesityrelated biomarkers.

This study aimed to assess the anti-diabetic activity in vitro of plant resources used in traditional medicine in north Newfoundland region of Canada. The extracts prepared from sweet gale (Myrica gale L.), roseroot (Rhodiola rosea L.), sheep sorrel (Rumex acetosa L.), stinging nettles (Utrica dioica L.), and dandelion (Taraxacum officinale L.) were used to compare their antioxidant and antidiabetic properties in vitro. The study was extended further to explore and evaluate the antiadipogenic ability of selected plant extracts in vitro using 3T3-L1 preadipocytes.

\section{MATERIALS AND METHODS}

\section{Chemicals}

The liquid chromatography standards: phloridzin, phloretin, chlorogenic acid, ferulic acid, and caffeic acid were purchased from Sigma Aldrich (Oakville, ON, Canada); catechin, epicatechin, quercetin, quercetin-3-O-galactoside and quercitin3-O-glucoside from ChromaDex, Inc. (Santa Ana, CA, USA); quercitin-3-O-rhamnoside, quercitin-3-O-galactoside and anthocyanin standards from Indofine Chemical Company (Hillsborough, NJ, USA). The analytic solvents, chemicals, and enzymes were obtained from Sigma Aldrich (Oakville, ON, Canada). Mouse embryo 3T3-L1 cell line (ATCC, CL-173) was obtained from Cedarlane (Burlington, ON, Canada). Phenazine methosulfate (PMS) and 3-(4,5-dimethylthiazol-2-yl)-5-(3carboxymethoxyphenyl)-2-(4-sulfophenyl)-2H-tetrazolium

(MTS) were purchased from Sigma-Aldrich Canada Ltd. (Oakville, ON, Canada). Dulbecco's modified Eagle's medium (DMEM), penicillin-streptomycin solution, fetal bovine serum, bovine calf serum, trypsin-EDTA solution, dexamethasone (DEX), 3-isobutyl-1-methylxanthine (IBMX), insulin solution and all other cell biology grade chemicals were purchased from Sigma-Aldrich (Oakville, ON, Canada). Lipolysis colorimetric assay kit was purchased from Biovison Inc. (Milpitas, CA, USA) and adipogenesis assay kit from Cayman Chemical Co. (Ann Arbor, MI, USA).

\section{Plant Materials}

All the plant materials used in this study were collected from the wild habitats of northern Newfoundland, Canada in the year 2015. After harvesting a bulk sample of approximately one $\mathrm{kg}$ from multiple growing locations, the samples were sub-divided into three replicates. The stems with leaves were cut into small chunks $(1 \mathrm{~cm})$ and were flash frozen in liquid nitrogen and freeze-dried in a freeze dryer (Kinetics, FTS Systems Inc, Stone Ridge, NY, USA) until constant weight was observed. The dried plant samples were ground in a coffee grinder (Model 6378-33, Sunbeam, China).

\section{Preparation of Hot Water Extractions (WE)}

Five grams of freeze-dried samples were extracted in $100 \mathrm{ml}$ of boiling water for $30 \mathrm{~min}$ (in triplicates), filtered through Whatman No. 4 paper under vacuum. The samples were reconstituted in dimethyl sulfoxide (DMSO). The supernatants were stored at $-80^{\circ} \mathrm{C}$ until further use for various assays.

\section{Preparation of Ethanolic Extractions (EE)}

Five grams of each sample was sonicated in $100 \mathrm{~mL}$ of absolute ethanol, three times for $15 \mathrm{~min}$ with $10 \mathrm{~min}$ intervals in between sonications (in triplicates). After the extraction, extracts were filtered separately using Whatman No. 1 filter papers under vacuum. The extracts were concentrated using a rotary evaporator (Rotavapor, R-200, Buchi, Flawil, Switzerland) at $37^{\circ} \mathrm{C}$, followed by nitrogen drying to evaporate ethanol. The extracts were then stored at $-80^{\circ} \mathrm{C}$ until further use.

\section{UPLC-MS/MS Analysis of Phenolic Compounds}

Analyses of major individual phenolic compounds present in freeze-dried plant extracts were performed according to a previously reported method (19). All analyses were conducted using ultra-pressure liquid chromatography (Waters, Milford, MA, USA) coupled with Micromass Quattro micro API tandem mass spectrometry (UPLC-MS/MS) system and controlled with Mass Lynx V4.0 data analysis system (Micromass, Cary, NC, USA). The column used was Aquity BEH $\mathrm{C}_{18}(100 \times 2.1 \mathrm{~mm}$, $1.7 \mu \mathrm{m}$ ) (Waters, Milford, MA, USA). For the separation of the flavonol, flavan-3-ol, phenolic acid and dihydrochalcone, the mobile phase consisted of $0.1 \%$ formic acid in water (solvent A) and $0.1 \%$ formic acid in acetonitrile (solvent B). A linear gradient profile was used with the following proportions of Solvent A applied at time $\mathrm{t}(\mathrm{min}) ;(\mathrm{t}, \mathrm{A} \%):(0,94 \%),(2,83.5 \%),(2.61,83 \%)$, $(2.17,82.5 \%),(3.63,82.5 \%),(4.08,81.5 \%),(4.76,80 \%),(6.75$, $20 \%),(8.75,94 \%)$, and $(12,94 \%)$.

Electrospray ionization in negative ion mode (ESI-) was used for the analysis of the flavonol, flavan-3-ol, phenolic acid, and dihydrochalcone; the following conditions were used: capillary voltage $3,000 \mathrm{~V}$, nebulizer gas $\left(\mathrm{N}_{2}\right)$ temperature $375^{\circ} \mathrm{C}$ at a flow 
rate of $0.35 \mathrm{~mL} / \mathrm{min}$. The settings for positive ion experiments were as follows: capillary voltage $(25-50 \mathrm{~V})$ was optimized for each individual compound. Multiple reaction-monitoring (MRM) mode using specific precursor/product ion transitions was employed for quantification in comparison with standards: $\mathrm{m} / \mathrm{z} 301 \rightarrow 105$ for quercetin (Q), m/z 609 $\rightarrow 301$ for Q-3-Orutinoside, $\mathrm{m} / \mathrm{z} 463 \rightarrow 301$ for $\mathrm{Q}-3-\mathrm{O}$-glucoside and $\mathrm{Q}-3-\mathrm{O}$ galactoside, $\mathrm{m} / \mathrm{z} 448 \rightarrow 301$ for Q-3-O-rhamnoside, $\mathrm{m} / \mathrm{z} 595 \rightarrow 301$ for Q-3-O-peltoside, $\mathrm{m} / \mathrm{z} 273 \rightarrow 167$ for phloritin, $\mathrm{m} / \mathrm{z} 435 \rightarrow 273$ for phloridzin, $\mathrm{m} / \mathrm{z} 353 \rightarrow 191$ for chlorogenic acid, $\mathrm{m} / \mathrm{z} 179 \rightarrow 135$ for caffeic acid, $\mathrm{m} / \mathrm{z} 193 \rightarrow 134$ for ferulic acid and isoferulic acid, $\mathrm{m} / \mathrm{z} 289 \rightarrow 109$ for catechin, $\mathrm{m} / \mathrm{z} 290 \rightarrow 109$ for epicatechin, and $\mathrm{m} / \mathrm{z} 305 \rightarrow 125$ for epigallocatechin. In MRM experiments, both quadrupoles were operated at unit resolution.

\section{Total Phenolic Content (TPC) by Folin-Ciocalteu Reagent Assay}

TPC was measured by Folin-Ciocalteu (FC) reagent using the method described by Singleton and Orthofer (20). FolinCiocalteu reagent $(0.2 \mathrm{~N})$ and $7.5 \%(\mathrm{w} / \mathrm{v})$ sodium carbonate $\left(\mathrm{Na}_{2} \mathrm{CO}_{3}\right)$ was prepared. At the first step, $20 \mu \mathrm{L}$ of samples were added into 96-well microplate, and $100 \mu \mathrm{L}$ of FC reagent was added to each well. After $5 \mathrm{~min}, 80 \mu \mathrm{L}$ of $\mathrm{Na}_{2} \mathrm{CO}_{3}$ were added, and the microplate was placed in the dark at room temperature for $2 \mathrm{~h}$. The absorbance of resultant color was read at $760 \mathrm{~nm}$ using a FLUOstar OPTIMA plate reader (BMG Labtech., Durham, NC, USA) and TPC values were expressed as mg gallic acid equivalents (GAE) per liter.

\section{Ferric Reducing Antioxidant Power (FRAP) Assay}

The FRAP was conducted based on the method described by Benzie and Strain (21) with some modifications (19). The reaction reagent was made freshly by mixing $300 \mathrm{mM}$ acetate buffer (pH 3.6), $10 \mathrm{mM}$ TPTZ solution, and $20 \mathrm{mM} \mathrm{FeCl}$ solution in the ratio of 10:1:1. The TPTZ solution was prepared on the same day of analysis. The Trolox standard solution (1 mM) was prepared in ethanol. Samples $(20 \mu \mathrm{L})$ were taken in the 96well microplate (COSTAR, 9017). The microplate with samples was incubated at $37^{\circ} \mathrm{C}$ for $15 \mathrm{~min}$. The working reagent (180 $\mu \mathrm{L}$ ) was injected into the sample wells by the plate reader programmed pump. The absorbance was read at $595 \mathrm{~nm}$ using FLUOstar OPTIMA plate reader. FRAP values were expressed as mg Trolox equivalents (TE) per liter.

\section{DPPH' Radical Scavenging Activity}

The assay was performed using the method of Shimada et al. (22) with some modifications (19). DPPH solution was prepared in 95\% ethanol, $100 \mu \mathrm{L}$ of this solution were mixed with $100 \mu \mathrm{L}$ of sample in 96-well microplate. Various concentrations (20, 40, 60,80 , and $100 \mu \mathrm{L}$ ) of the extracts were used. The mixture was incubated for $30 \mathrm{~min}$ at room temperature. The absorbance of resulted color was read at $517 \mathrm{~nm}$ using the plate reader. The $\mathrm{DPPH}^{\cdot}$ scavenging activity was expressed as an $\mathrm{IC}_{50}$ value (the concentration of the antioxidant required to scavenge $50 \%$ of $\mathrm{DPPH}^{\bullet}$ present in the test solution.

\section{$\alpha$-Amylase Inhibitory Assay}

The pancreatic porcine $\alpha$-amylase assay was adapted from Sudha et al. (23) with modifications (17). Briefly, both EE and WE were freeze-dried to obtain a completely dry powder. The test extracts enzyme and soluble starch were dissolved in $20 \mathrm{mM}$ sodium phosphate buffer containing $6 \mathrm{mM} \mathrm{NaCl}$ ( $\mathrm{pH}$ 6.9). The test extracts at different concentrations were dissolved in the buffer solution. To a test tube, $250 \mu \mathrm{L}$ of pancreatic porcine $\alpha$ amylase $(1 \mathrm{U} / \mathrm{mL}$, dissolved in the buffer $(\mathrm{pH}$ 6.9) and $100 \mu \mathrm{L}$ of test extract at a concentration ranging from 15.6 to $250 \mathrm{mg} / \mathrm{L}$ were added. The mixture was pre-incubated at $37^{\circ} \mathrm{C}$ for $15 \mathrm{~min}$, before the addition of $250 \mu \mathrm{L}$ of $0.5 \%$ starch. The mixture was then vortexed and incubated again at $37^{\circ} \mathrm{C}$ for $15 \mathrm{~min}$ followed by the reaction termination using $1 \mathrm{~mL}$ of dinitrosalicylic acid color reagent. The tubes were placed in a boiling water bath for $5 \mathrm{~min}$, cooled to room temperature and diluted. Two hundred microliters of the reaction mixture were taken into a 96-well clear plate, and the absorbance was read at $540 \mathrm{~nm}$ using the FLUOstar OPTIMA plate reader. The control $\alpha$-amylase at $1 \mathrm{U} / \mathrm{mL}$ without any inhibitor represented $100 \%$ enzyme activity. Appropriate test extract controls containing the reaction mixture except the enzyme were used to correct for the color interference. A known $\alpha$-amylase inhibitor, acarbose was used for comparison studies. The percentage inhibition of the test sample on $\alpha$-amylase was calculated as:

$$
\text { Inhibition }(\%)=100 \times(A C-A S) /(A C)
$$

Where AS, AC is the absorbance of sample and control, respectively. The results were expressed in terms of $\mathrm{IC}_{50}$ representing the concentration of test extracts required to cause the enzyme inhibition by $50 \%$.

\section{$\alpha$-Glucosidase Inhibitory Assay}

The $\alpha$-glucosidase inhibitory assay was adapted from Li et al. (24) with modification. Briefly, both EE and WE were freezedried to obtain a completely dry powder. From this powder, various concentrations of each extract were prepared in $10 \mathrm{mM}$ potassium phosphate buffer ( $\mathrm{pH}$ 6.8). To a 96-well clear plate, a reaction mixture containing $20 \mu \mathrm{L}$ extract at different concentrations, $20 \mu \mathrm{L} \alpha$-glucosidase $(0.5 \mathrm{U} / \mathrm{mL})$ and $60 \mu \mathrm{L}$ of $10 \mathrm{mM}$ potassium phosphate buffer $(\mathrm{pH} 6.8)$ were pre-incubated at $37^{\circ} \mathrm{C}$ for $15 \mathrm{~min}$ before adding $20 \mu \mathrm{L}$ of $5 \mathrm{mM}$ p-nitrophenol$\alpha$-D-glucopyranoside substrate. The mixture was then incubated at $37^{\circ} \mathrm{C}$ for the reaction to take place. After $15 \mathrm{~min}, 80 \mu \mathrm{L}$ of stop solution containing $200 \mathrm{mM}$ sodium carbonate was added. Then the absorbance at $405 \mathrm{~nm}$ was recorded using the microplate reader. The positive control sample was the mixture of the enzyme and substrate without inhibitors. The sample controls and blanks were the mixtures of sample and control, respectively, except $\alpha$-glucosidase was instead with buffer, respectively. The inhibition (\%) of the test sample on $\alpha$ glucosidase was calculated same way as with $\alpha$-amylase assay. Acarbose, a prescribed drug for $\alpha$-glucosidase inhibition, was also used for comparison purpose. 

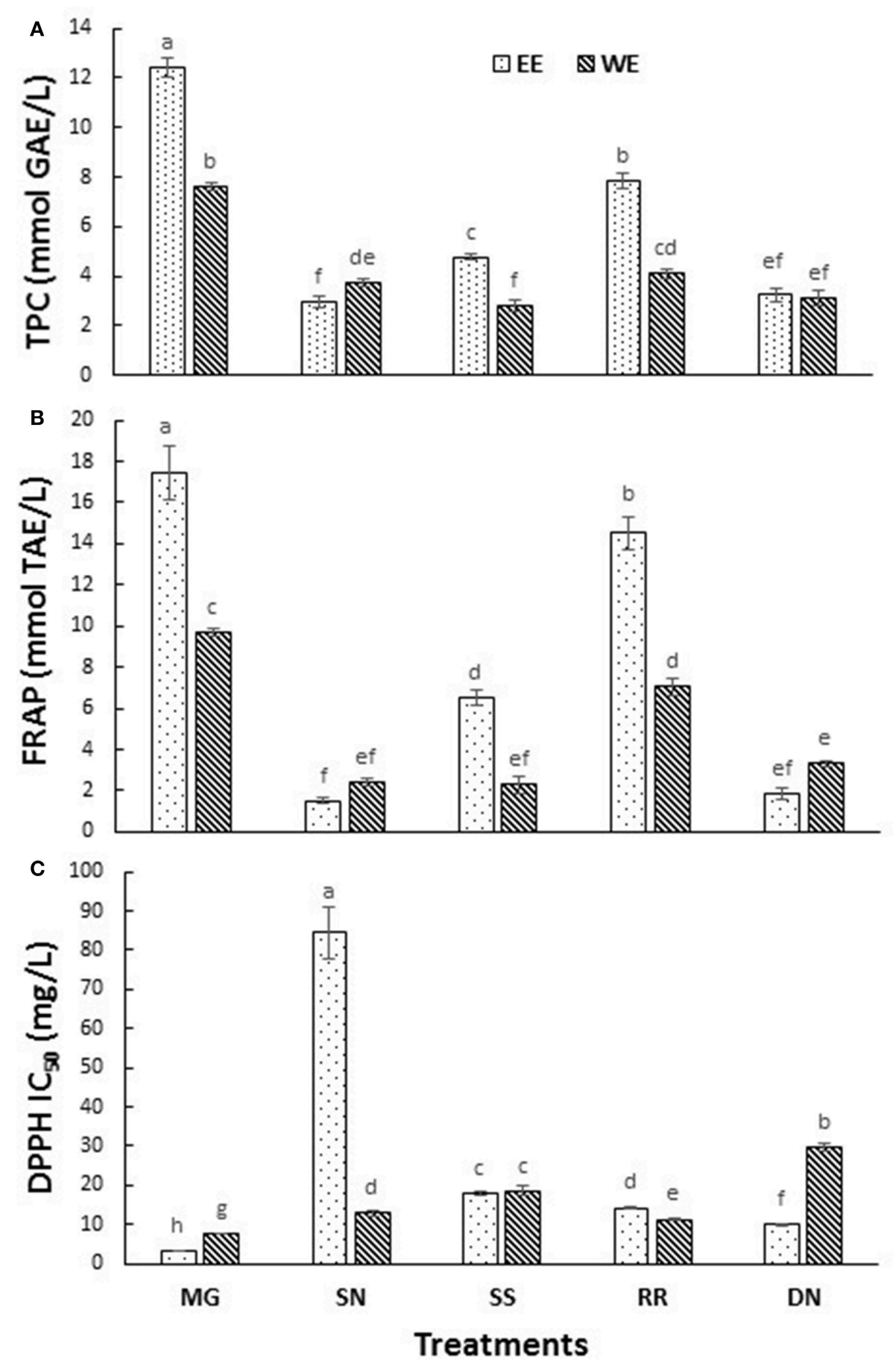

FIGURE 1 | The total phenolic content (A), FRAP (B), and DPPH radical scavenging activity (C) measured in the tested hot water and ethanol plant extracts. Values are the mean \pm SD of triplicate experiments. Different letters denote significant differences ( $p \leq 0.05$, Tukey's test). MG, Myrica gale; SN, stinging nettles; SS, sheep sorrel; RR, roseroot; DN, dandelions.

\section{Inhibition of AGE Formation}

The procedure was based on previous methods (25) with minor modifications (17). The incubation mixtures are in a final volume of $1.0 \mathrm{ml}$, containing Bovine serum albumin (BSA, $5.0 \mathrm{mg} / \mathrm{ml}$ ) and D-glucose $(36 \mathrm{mg} / \mathrm{ml})$ and vehicle (Control) or the inhibitor at $0.01,0.02,0.04,0.05,0.1,0.2,0.5,1.0 \mathrm{mg} / \mathrm{ml}$ concentrations or aminoguanidine ( $\mathrm{AG}, 1.0 \mathrm{mg} / \mathrm{ml})$. Aminoguanidine, a known AGE formation inhibitor, was used as a positive control. All 
TABLE 1 | UPLC-MS/MS quantification of selected major phenolic compounds (mg/L) present in ethanol and hot water plant extracts.

\begin{tabular}{|c|c|c|c|c|c|}
\hline Phenolic Group & MG & SN & sS & $\mathbf{R R}$ & DN \\
\hline \multicolumn{6}{|l|}{ ETHANOL EXTRACT } \\
\hline Flavonols & $223.2 \pm 1.2$ & $7.6 \pm 0.1$ & $148.6 \pm 4.4$ & $32.0 \pm 0.6$ & $5.3 \pm 0.1$ \\
\hline Dihydrochalcones & $2.5 \pm 0.0$ & ND & $1.8 \pm 0.1$ & $0.1 \pm 0.0$ & $0.1 \pm 0.0$ \\
\hline Phenolic acids & $12.0 \pm 0.4$ & $20.1 \pm 0.2$ & $145.2 \pm 18.2$ & $4.1 \pm 0.2$ & $85.6 \pm 0.9$ \\
\hline Total Phenolics (UPLC-MS/MS) & 237.7 & 27.7 & 295.6 & 36.2 & 91 \\
\hline \multicolumn{6}{|l|}{ HOT WATER EXTRACT } \\
\hline Flavonols & $133.4 \pm 1.9$ & $1.5 \pm 0.1$ & $51.0 \pm 3.4$ & $14.9 \pm 0.2$ & $0.1 \pm 0.3$ \\
\hline Dihydrochalcones & ND & ND & ND & $0.1 \pm 0.1$ & ND \\
\hline Phenolic acids & $7.7 \pm 0.6$ & $37.1 \pm 0.5$ & $82.3 \pm 6.9$ & $3.8 \pm 0.1$ & $0.4 \pm 0.2$ \\
\hline Total Phenolics (UPLC-MS/MS) & 141.1 & 38.6 & 133.3 & 19.6 & 0.6 \\
\hline
\end{tabular}

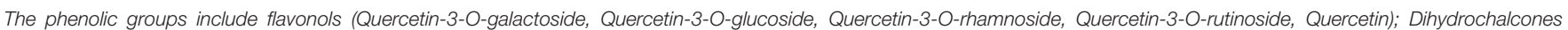

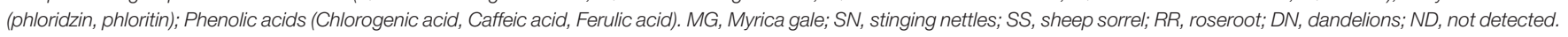

these solutions were dissolved in $0.2 \mathrm{M}$ phosphate buffer saline ( $\mathrm{pH} 7.4)$ containing sodium azide $(0.02 \% \mathrm{w} / \mathrm{v})$. The mixtures in screw-capped test tubes were incubated in triplicate in an incubator at $37^{\circ} \mathrm{C}$ for a week. Fluorescent AGE was monitored on a microplate reader using 340 and $420 \mathrm{~nm}$ as the excitation and emission wavelengths. Experiments were conducted in triplicates. Percentage of the AGE inhibition was calculated by the following equation:

$$
\text { inhibition }(\%)=\left[1-\left(\frac{\text { Fluorescence of the test }}{\text { Fluorescence of control }}\right)\right] \times 100
$$

\section{T3-L1 Cell Culture}

Mouse embryo 3T3-L1 cell line (ATCC, CL-173) was obtained from Cedarlane (Burlington, ON, Canada). The 3T3-L1 preadipocytes were grown in Dulbecco's Modified Eagle's Medium (DMEM) supplemented with $10 \%$ fetal bovine serum (FBS). The culture was maintained at $37^{\circ} \mathrm{C}$ in a humidified atmosphere, containing $5 \% \mathrm{CO}_{2}$. For adipocyte differentiation, the 3T3-L1 cells were grown in 96-well plates $\left(0.2 \%\right.$ gelatin-coated) at cell density $2.0 \times 10^{4}$ cell/well to confluence for $48 \mathrm{~h}$. After incubating, preadipocytes were stimulated by a differentiation medium containing $1 \mu \mathrm{M}$ dexamethasone (DEX) (Sigma Aldrich, Canada), $0.5 \mathrm{mM} \mathrm{3-}$ isobutyl-1-methylxanthanine (IBMX) (Sigma Aldrich, Canada) and $1 \mu \mathrm{g} / \mathrm{mL}$ insulin in DMEM with 10\% FBS. After 2 days the medium was replaced with DMEM containing 10\% FBS and $1 \mu \mathrm{g} / \mathrm{mL}$ insulin and corresponding treatment compounds were added for further analysis.

\section{Adipocyte Cell Viability Assay}

Cell viability was determined using the 3-(4,5-dimethylthiazol2-yl)-5-(3-carboxymethoxyphenyl)-2-(4-sulfophenyl)-2H-

tetrazolium (MTS) assay (26). The 3T3-L1 preadipocytes were grown in 96-well plates at the cell density of $2.5 \times 10^{4} /$ well and treated with 50 and $100 \mu \mathrm{g} / \mathrm{mL}$ of plant extracts concentrations for $48 \mathrm{~h}$ at $37^{\circ} \mathrm{C}$. The cells were incubated in the presence of MTS and PMA for $3 \mathrm{~h}$ at $37^{\circ} \mathrm{C}$. The absorbance was measured at
$570 \mathrm{~nm}$ using a FLUOstar OPTIMA plate reader (BMG Labtech, Durham, NC, USA).

\section{Determination of Lipid Accumulation by Oil Red O Staining}

The Oil red $\mathrm{O}$ assay was conducted on differentiated adipocytes on day 10 in 96-well plate using adipogenesis assay kit from Cayman Chemicals (Ann Arbor, MI, US). The medium was removed from the wells and cells were fixed with $75 \mu \mathrm{L}$ lipid droplet assay fixative. After $15 \mathrm{~min}$ incubation, the wells were washed five times with $100 \mu \mathrm{L}$ wash solution. The Oil red $\mathrm{O}$ working solution $(75 \mu \mathrm{L})$ was added to the wells and incubated for $20 \mathrm{~min}$. The Oil red $\mathrm{O}$ solution was removed at the end of incubation, and the wells were washed with wash solution until no visible pink color in the wash. The pictures were taken under a microscope. The dye was extracted with $100 \mu \mathrm{L}$ dye extraction solution. The absorbance was read at $490 \mathrm{~nm}$ using a FLUOstar OPTIMA plate reader (BMG Labtech, Durham, NC, USA).

\section{Statistical Analysis}

All the experiments were performed in triplicates, and complete randomized designs were used. The normality of the residuals was tested using the Anderson-Darling test. The variables were tested using one-way analysis of variance (ANOVA), and the multiple mean comparisons were performed in SAS V8, Cary, NS, USA) with Tukey's test. The data are expressed as a mean \pm standard deviation.

\section{RESULTS AND DISCUSSION}

\section{Total Phenolic Content and Antioxidant Capacity of Hot Water and Ethanol Extracts}

The postprandial blood glucose level is the primary factor to maintain in the management of T2D. The current antihyperglycemic strategies include 11 major classes of antidiabetic agents [sulfonylureas, meglitinides, biguanides, thiazolidinediones, $\alpha$-glucosidase inhibitors, glucagon-like peptide-1 receptor agonists, dipeptidyl peptidase-IV inhibitors, amylin analogs, dopamine D2-receptor agonists, bile acid 
sequestrants and insulin (3)]. The drug intervention has also been associated with inexorable side effects, mainly hypoglycemia, weight gain and gastrointestinal discomfort (7).
The antioxidant effects attributed to the polyphenols of plants plays a pivotal role in protecting the body from oxidative stress, diabetes, cardiovascular diseases, and cancer. Therefore, the

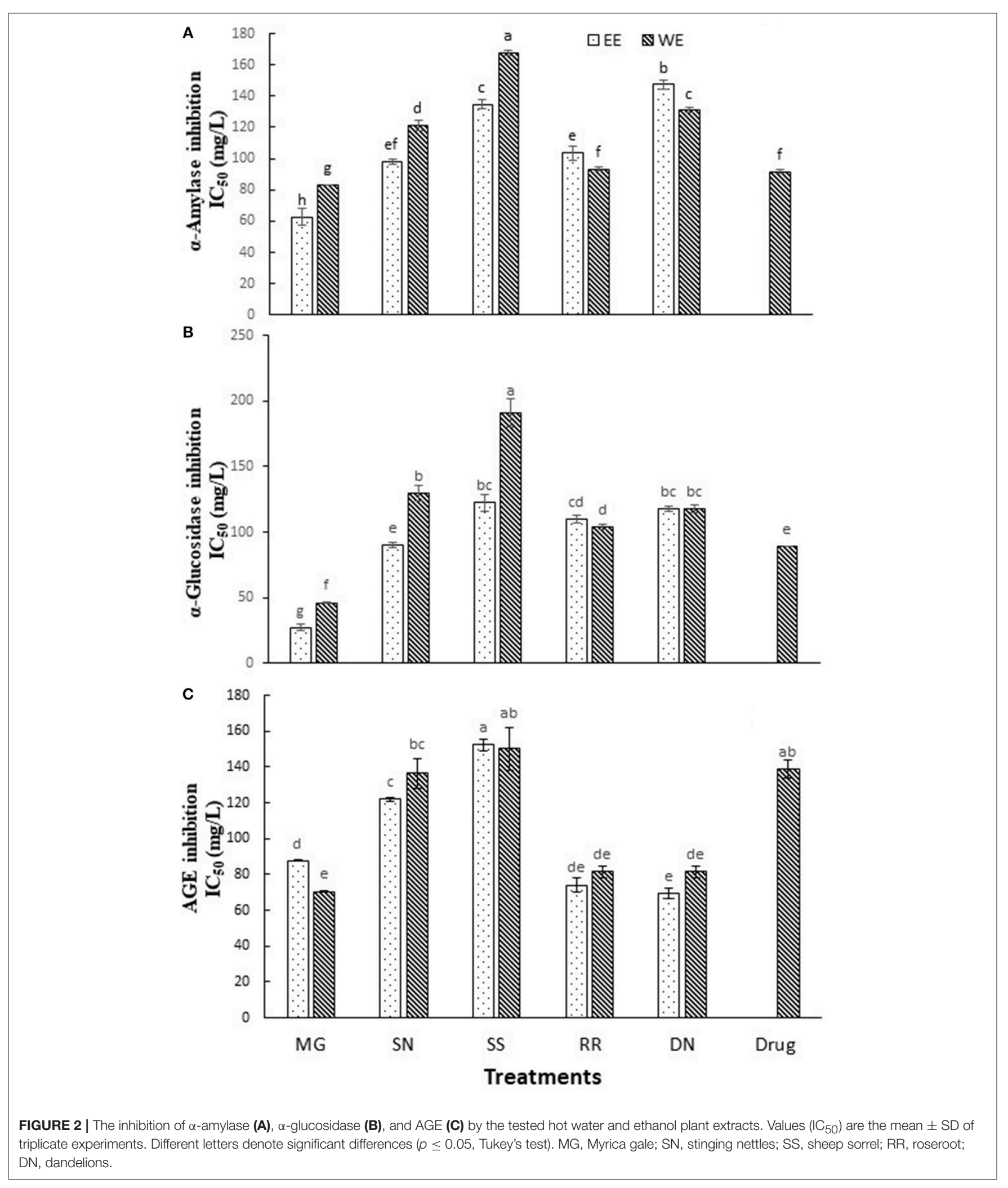


TABLE 2 | Pearson correlation coefficients to exhibit linear relationship among the total phenolic compounds, FRAP, DPPH, $\alpha$-amylase, $\alpha$-glucosidase, and AGE in ethanol and hot water plant extracts.

\begin{tabular}{|c|c|c|c|c|c|c|}
\hline Extract & Total FC phenolics & FRAP & DPPH & $\alpha$-Amylase & $\alpha$-Glucosidase & AGE \\
\hline \multicolumn{7}{|l|}{ ETHANOL } \\
\hline FRAP & 0.95 & & & & & \\
\hline DPPH & $-0.55^{\star}$ & $-0.57^{\star}$ & & & & \\
\hline$\alpha$-Amylase & $-0.78^{*}$ & $-0.69^{*}$ & $-0.08^{\star}$ & & & \\
\hline$\alpha$-Glucosidase & -0.78 & $-0.61^{*}$ & $0.09^{\star}$ & 0.90 & & \\
\hline AGE & $-0.31^{*}$ & $-0.31^{*}$ & $0.41^{*}$ & $0.14^{*}$ & $0.19^{*}$ & \\
\hline UPUPLC-MS/MS /MS total phenolics & $0.37^{\star}$ & $0.29^{\star}$ & $-0.49^{\star}$ & $-0.04^{*}$ & $-0.24^{*}$ & $0.50^{*}$ \\
\hline \multicolumn{7}{|l|}{ HOT WATER } \\
\hline FRAP & 0.89 & & & & & \\
\hline DPPH & $-0.68^{\star}$ & $-0.63^{\star}$ & & & & \\
\hline$\alpha$-Amylase & $-0.78^{*}$ & $-0.86^{\star}$ & $0.60^{*}$ & & & \\
\hline$\alpha$-Glucosidase & $-0.87^{\star}$ & $-0.86^{\star}$ & $0.46^{*}$ & 0.93 & & \\
\hline AGE & $-0.59^{\star}$ & $-0.78^{\star}$ & $0.074^{*}$ & $0.79^{\star}$ & $0.85^{\star}$ & \\
\hline UPUPLC-MS/MS/MS total phenolics & 0.98 & $0.79^{\star}$ & $-0.69^{\star}$ & $-0.70^{*}$ & $-0.81^{*}$ & $-0.46^{\star}$ \\
\hline
\end{tabular}

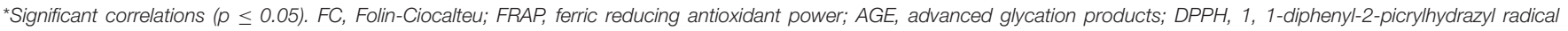
scavenging activity (IC50); UPLC-MS/MS, ultra-pressure liquid chromatography-mass spectrometry.

plant-based therapeutics is a potential alternative therapy to explore due to their reported safety and nutraceutical benefits (27). To compare the total phenolics and antioxidant capacity of the EE and WE of five medicinal plant material, TPC (Folin Caiocalteu), FRAP, and DPPH radical scavenging assays were performed (Figure 1). The total phenolic content was the highest in Myrica gale EE (12.4 mmol GAE/L), followed by roseroot $\mathrm{EE}(7.8 \mathrm{mmol} \mathrm{GAE} / \mathrm{L})$. Roseroot plant is rich in flavonoids and phenolic glycosides: salidrosides and rosavins (28). Similarly, Myrica gale (17.4 mmol TE/L) and roseroot (14.5 mmol TE/L) had greater FRAP values in corresponding EE. Total phenolic content and FRAP values were noticeably high in EE compared to WE. The DPPH radical scavenging activity was highest in EE of Myrica gale, roseroot, dandelion and roseroot $\mathrm{WE}\left(\mathrm{IC}_{50}=\right.$ $3.3,14.2,9.8,11.3 \mathrm{mg} / \mathrm{L}$, respectively). Similar to our finding, Myrica gale ethanol extracts have been reported to exert strong antioxidant capacity due to the presence of phenolic compounds (Table 1) (29). The reports are scarce on the identification of phenolic compounds in Myrica gale stem and leaves. Our findings indicate that the overall antioxidant capacity was higher in $\mathrm{EE}$ as compared to the corresponding WE.

\section{Antidiabetic Activity in vitro}

Dietary polyphenols, in addition to their antioxidant effects, have been reported to exert anti-hyperglycemic effects by binding to glucose transporters (3) and competitive inhibition of digestive enzymes (16). Carbohydrate hydrolyzing enzymes, $\alpha$ amylase and $\alpha$-glucosidase digest dietary starch and degrade the oligosaccharides to glucose, resulting postprandial glucose surge. Therefore, inhibition of $\alpha$-amylase and $\alpha$-glucosidase activities is one of the primary approaches to manage hyperglycemic conditions of T2D patients. Acarbose is the most commonly prescribed $\alpha$-glucosidase inhibitory drug. The inhibition of $\alpha$-amylase, $\alpha$-glucosidase activity and $\mathrm{AGE}$ ( $\mathrm{IC}_{50}$ values) by the tested plant extracts is described in Figure 2. Myrica gale ethanol extract exhibited the highest inhibition of $\alpha$-glucosidase with $\mathrm{IC}_{50}$ values $(27 \mathrm{mg} / \mathrm{L})$ which was significantly efficacious compared to the drug, acarbose $\mathrm{IC}_{50}$ value ( $\alpha$-glucosidase, 89 $\mathrm{mg} / \mathrm{L})$. The polyphenols are known to interact with the enzyme through non-specific binding, leading to inhibition of enzyme activity. The polyphenols tend to more effective on $\alpha$-glucosidase inhibition with increase with molecular weight and degree of polymerization (30).

The extracts of dandelion (EE), roseroot (EE) and Myrica gale (WE) exhibited significant inhibition of formation of AGE $\left(\mathrm{IC}_{50}=69.4,74.0,70.4 \mathrm{mg} / \mathrm{L}\right.$, respectively) (Figure 2C), compared to common anti-glycation drug aminoguanidine $\left(\mathrm{IC}_{50}=138 \mathrm{mg} / \mathrm{L}\right)$. A previous study has reported that wild raspberry stem and blackberry stem extracts had stronger antiglycation properties than aminoguanidine (17). Dandelion is used in traditional anticancer and antimicrobial medicines; however, only a few reports are available on its phytochemical analysis. According to the previous studies, dandelion shoots contain hydroxycinnamic acid, luteolin and flavonoid glycosides $(18,31)$. Dandelion phenolic fraction showed an inhibitory action on $\mathrm{H}_{2} \mathrm{O}_{2}$ and $\mathrm{H}_{2} \mathrm{O}_{2} / \mathrm{Fe}$-induced oxidation in human plasma in vitro (18) and protected against oxidative stress linked atherosclerosis in vivo (32).

\section{Correlation Analysis of Total Phenolics, Antioxidant Capacity, and Antidiabetic Activity}

Plant polyphenols could modulate various enzymes and immune cells in the human body, apart from their antioxidant potential $(33,34)$. Pearson correlation was applied to total FC phenolics, $\mathrm{DPPH}^{\bullet}$ scavenging activity, FRAP, $\alpha$-amylase and $\alpha$-glucosidase activity (Table 2 ). $\mathrm{DPPH}^{\bullet}$ scavenging activity exhibited significant non-linear correlation with TPC $(r=-0.55$; 
$p=0.33, r=-0.68 ; p=0.25)$, FRAP $(r=-0.57 ; p=0.30$, $r=-0.63 ; p=0.27)$, a linear correlation with $\alpha$-amylase in WE $(r=0.60 ; p=0.27), \alpha$-glucosidase activity $(r=0.09$; $p=0.88 ; r=0.46 ; p=0.44)$ and AGE $(r=0.41 ; p=0.48$; $r=0.07 ; p=0.90)$ in EE and WE, respectively. Similarly, a negative correlation of $\mathrm{DPPH}^{\bullet}$ scavenging activity was reported with FRAP and TPC (17). TPC and AGE exhibited significant negative relationship in both $\mathrm{EE}$ and WE $(r=-0.31 ; p=$ $0.60 ; r=-0.59 ; p=0.29)$. However, UPLC-MS/MS total phenolics depicted a significant linear correlation with AGE in $\mathrm{EE}(r=0.50 ; p=0.38)$ and non-linear relationship in $\mathrm{WE}$ $(r=-0.46 ; p=0.43)$. There was no significant correlation between $\alpha$-glucosidase and $\alpha$-amylase activity $(p<0.05)$ in both $\mathrm{EE}$ and WE; however, FRAP values demonstrated significant negative correlation with $\alpha$-amylase $(r=-0.69 ; p=0.27$, $r=-0.86 ; p=0.06), \alpha$-glucosidase activity $(r=-0.61 ; p=0.28$; $r=-0.86 ; p=0.06)$ and AGE $(r=-0.31 ; p=0.61 ; r=-0.78$; $p=0.12$ ) in EE and $\mathrm{WE}$, respectively. The AGE values in both EE and WE showed a significant linear correlation with $\alpha$-amylase and $\alpha$-glucosidase $(r=0.14 ; p=0.82 ; r=0.79$; $p=0.11, r=0.19 ; p=0.75 ; r=0.85 ; p=0.07$, respectively). However, there was no significant correlation between TPC,

\section{A}

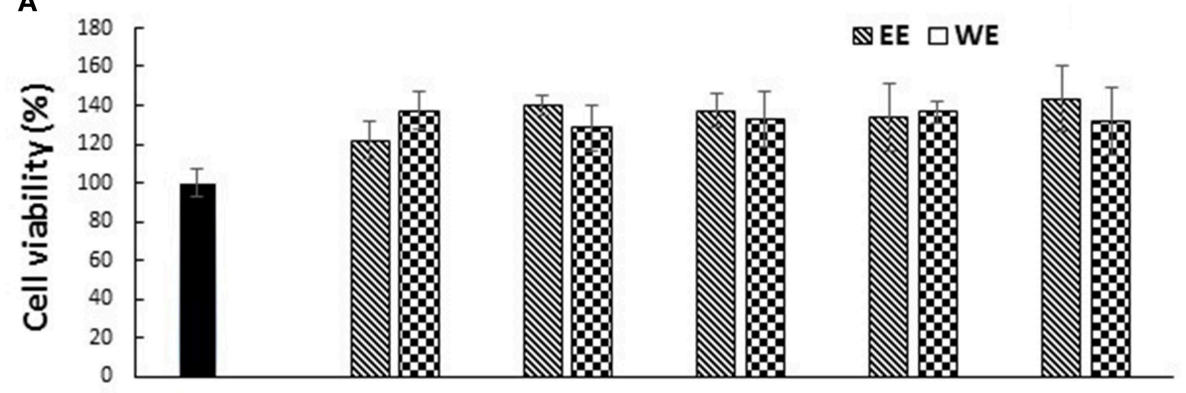

B
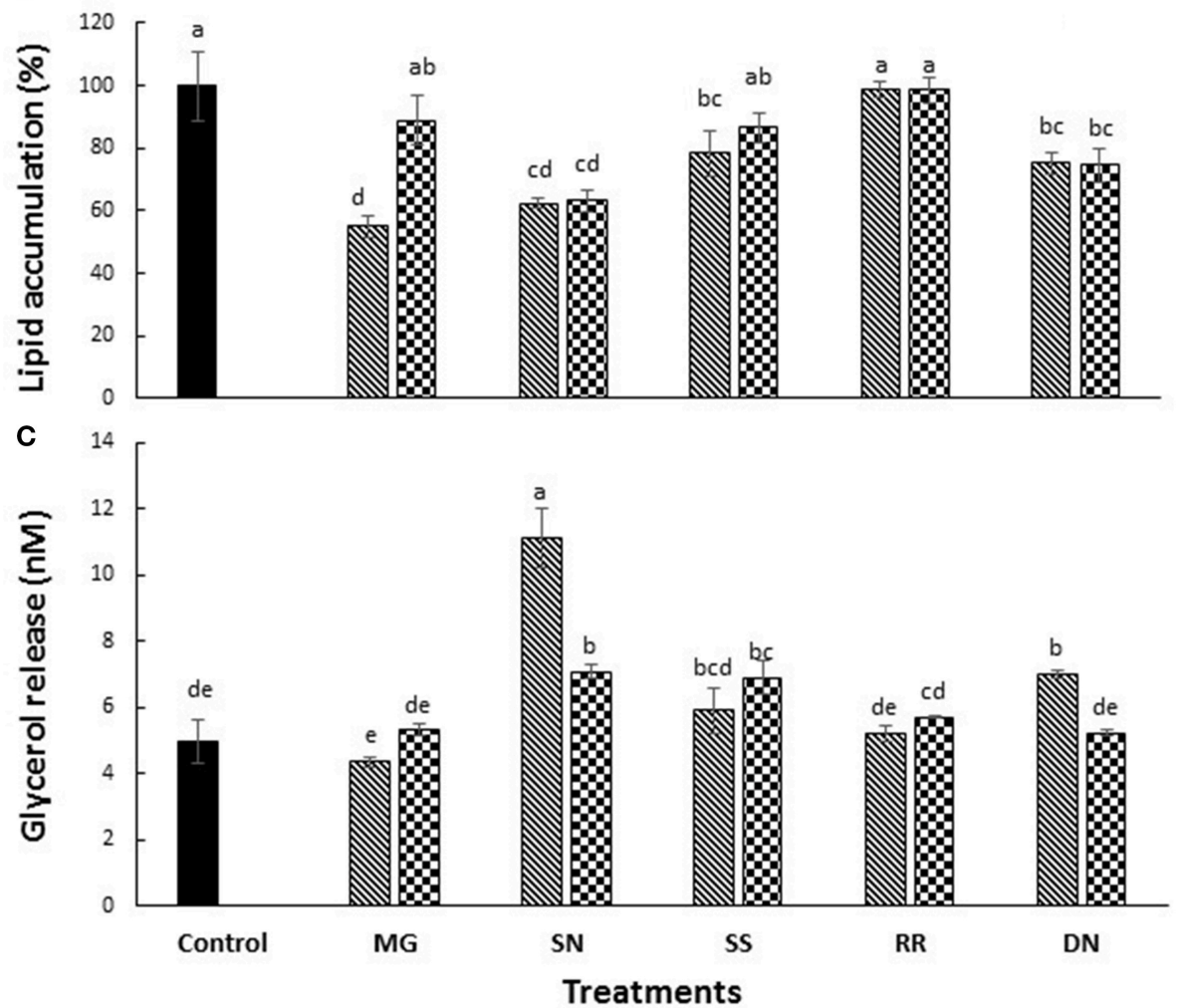

FIGURE 3 | The effect of plant extracts on cell viability (A), adipogenesis measured by \% lipid accumulation (B), and glycerol release (C) in 3T3-L1 adipocytes. The 3T3-L1 cells were treated with five test plant extracts $(50 \mu \mathrm{g} / \mathrm{mL})$ for $48 \mathrm{~h}$ to measure the cell viability. Differentiation was induced in 3T3-L1 pre-adipocytes two-days post-confluence. The cells were treated with plant extracts $(50 \mu \mathrm{g} / \mathrm{ml})$ for 7 days for lipolysis assay, and glycerol release was measured. The lipid content was analyzed on day 10 post-confluence. Values are the mean \pm SD of triplicate experiments. Different letters denote significant differences $(p \leq 0.05$, Tukey's test). MG, Myrica gale; SN, stinging nettles; SS, sheep sorrel; RR, roseroot; DN, dandelions. 
FRAP, $\alpha$-glucosidase activity $(p<0.05)$ in EE. On the other hand, TPC demonstrated a strong negative correlation with $\alpha$-amylase $(r=-0.78 ; p=0.12)$ and $\alpha$-glucosidase activity $(r=-0.87$; $p=0.06)$ in hot WE. The reducing power of phenolics based on their ability to reduce $\mathrm{Fe}^{3+}$ to $\mathrm{Fe}^{2+}$ is a potent antioxidant mechanism and express the concentration of electron donating compounds. The UPLC-MS/MS total phenolic content showed significant linear correlation $(r=0.29 ; p=0.63 ; r=0.79$; $p=0.11)$ with FRAP values. TPC showed significant linear correlation in $\mathrm{EE}(r=0.37 ; p=0.53)$, however no significant correlation was observed in WE. This might be attributed to the phenolic compounds under detection in UPLC-MS/MS analysis. The free radical quenching ability is an important link to prevent the oxidative stress related to hyperglycemia (35). The enzyme inhibitory activity was not linearly correlated to TPC of the extracts; however, it was associated with individual type of phenolic compound (9). ROS are generated during process of protein glycation and diabetic patients show elevated levels of iron and copper ions. The phenolic compounds have been reported to scavenge radicals generated in the glycation process and therefore, $\mathrm{DPPH}^{\bullet}$ scavenging activity and inhibition of AGE showed a strong correlation for polyphenols-rich plant extracts (36). The present correlation analysis indicates that $\alpha$-amylase, $\alpha$-glucosidase, and AGE inhibition ability of the studied EE and WE could be attributed to their FRAP and DPPH ${ }^{\bullet}$ scavenging properties.

\section{Antiadipogenic Effect of Test Compounds in 3T3-L1 Preadipocytes}

The cytotoxicity of EE and WE of Myrica gale, stinging nettles, sheep sorrel, roseroot and dandelion $(50,100 \mu \mathrm{g} / \mathrm{mL}$ ) was determined using MTS assay. Cell viability was above $80 \%$ for the concentration $(50 \mu \mathrm{g} / \mathrm{mL})$ of treatment compounds used in this study (Figure 3A).

Obesity is characterized by an increase in fat cells along with an increase in the size of lipid droplets in the cells, as a result of adipogenesis. Therefore, one of the target anti-obesity mechanism is to increase lipolysis and decrease adipogenesis (15). The influence of native medicinal plant extracts on the regulation of adipogenesis and lipolysis in 3T3-L1 cells was analyzed. The microscopic images of cells stained with Oil red $\mathrm{O}$ dye showed that size of lipid droplets was smaller in Myrica gale (EE), stinging nettles (EE, WE), sheep sorrel (EE), and dandelion extracts (EE, WE) in Figure 4. The intracellular lipid accumulation was measured by Oil red $\mathrm{O}$ assay to compare the $\%$ adipogenesis between treatments in Figure 3B. Myrica gale EE treatment had significantly lower adipogenesis $(54.8 \%$; $p \leq 0.05)$, followed by stinging nettles extracts $(62.2-63 \%$; $p \leq$ $0.05)$ and dandelions extracts (74.5-75.2\%; $p \leq 0.05)$ compared to the control (0.1\% DMSO). However, stinging nettles EE demonstrated significantly higher lipolysis $(11.1 \mathrm{nmol}$ glycerol release) compared to the control $(4.9 \mathrm{nmol})$, followed by stinging nettles WE $(7.0 \mathrm{nmol})$, sheep sorrel EE and WE $(5.9,6.9 \mathrm{nmol})$, and dandelion EE (6.9 nmol) $(p \leq 0.05)$ (Figure 3C). The stinging nettles $\mathrm{EE}$ and WE have mainly phenolic acids according to the UPLC-MS/MS analysis and WE also exhibited high DPPH ${ }^{\bullet}$ scavenging ability. Therefore, the results suggest that phenolic acids might have the ability to induce lipolysis by scavenging ROS. Water-soluble phenolics have been reported to have similar ROS scavenging ability and lipolysis potential (37). Several in vivo studies have revealed that increasing lipolysis in adipocytes does not increase circulating fatty acids and facilitate fatty acid
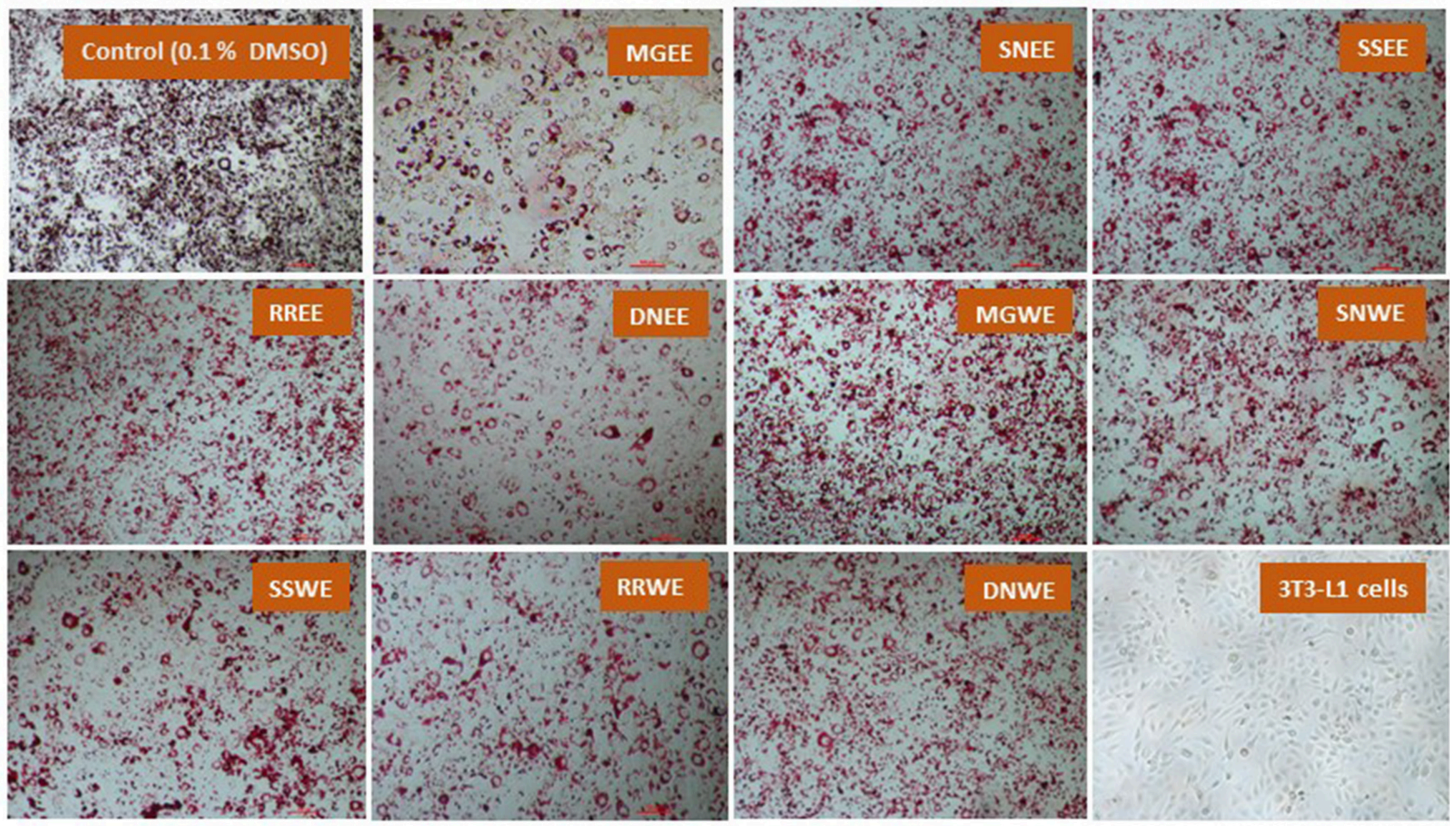

FIGURE 4 | The effect of plant extracts on adipogenesis in differentiated 3T3-L1 preadipocytes (day 10) using Oil red O assay. The concentration of the extracts was 50 mg/ mL. MG, Myrica gale; SN, stinging nettles; SS, sheep sorrel; RR, roseroot; DN, dandelions; EE, ethanolic extract; WE, hot water extracts. 
oxidation within the adipocytes $(38,39)$. Similar to our results, another research study on Momordica charantia plant extracts has reported that inhibition of adipogenesis might not be related to increasing in lipolysis (38). Hence, the decrease in glycerol release may be linked to decreased intracellular lipids in Myrica gale treatments infusion.

\section{CONCLUSION}

The present study provides the first pharmacological insight into the antioxidant and antidiabetic potential of the selected Canadian traditional medicinal plants. Myrica gale and roseroot extracts showed high antioxidant capacity. These traditional medicinal plant extracts also reduced significantly $\alpha$-amylase and $\alpha$-glucosidase activities compared to the most common drug, acarbose, indicating that the polyphenols present in the extracts have potential to reduce postprandial hyperglycemia by delaying the carbohydrate digestion. The antidiabetic ability to inhibit $\alpha$-amylase, $\alpha$-glucosidase enzymes, and AGE are needed to be further explored using in vivo experimental models to validate

\section{REFERENCES}

1. Upadhyay J, Polyzos SA, Perakakis N, Thakkar B, Paschou SA, Katsiki N, et al. Pharmacotherapy of type 2 diabetes: an update. Metabolism. (2018) 78:13-42. doi: 10.1016/j.metabol.2017.08.010

2. Guariguata L, Whiting DR, Hambleton I, Beagley J, Linnenkamp U, Shaw JE. Global estimates of diabetes prevalence for 2013 and projections for 2035. Diabetes Res Clin Pract. (2014) 103:137-49. doi: 10.1016/j.diabres.2013.11.002

3. Lacroix IME, Li-Chan ECY. Overview of food products and dietary constituents with antidiabetic properties and their putative mechanisms of action: a natural approach to complement pharmacotherapy in the management of diabetes. Mol Nutr Food Res. (2014) 58:61-78. doi: $10.1002 / \mathrm{mnfr} .201300223$

4. Kawser Hossain M, Abdal Dayem A, Han J, Yin Y, Kim K, Kumar Saha S, et al. Molecular mechanisms of the anti-obesity and anti-diabetic properties of flavonoids. Int J Mol Sci. (2016) 17:569. doi: 10.3390/ijms17040569

5. Chang AM, Smith MJ, Bloem CJ, Galecki AT, Halter JB. Effect of lowering postprandial hyperglycemia on insulin secretion in older people with impaired glucose tolerance. AJP Endocrinol Metab. (2004) 287:E906-11. doi: $10.1152 /$ ajpendo.00156.2004

6. Bhandari MR, Jong-Anurakkun N, Hong G, Kawabata J. $\alpha$-Glucosidase and $\alpha$-amylase inhibitory activities of nepalese medicinal herb pakhanbhed (Bergenia ciliata, Haw.). Food Chem. (2008) 106:247-52. doi: 10.1016/j.foodchem.2007.05.077

7. Rupasinghe HPV, Sekhon-Loodu S, Mantso T, Panayiotidis MI. Phytochemicals in regulating fatty acid $\beta$-oxidation: Potential underlying mechanisms and their involvement in obesity and weight loss. Pharmacol Ther. (2016) 165:153-63. doi: 10.1016/j.pharmthera.2016.06.005

8. Vinson JA, Howard TB. Inhibition of protein glycation and advanced glycation end products by ascorbic acid and other vitamins and nutrients. $J$ Nutr Biochem. (1996) 7:659-63. doi: 10.1016/S0955-2863(96)00128-3

9. Ademiluyi AO, Oboh G. Soybean phenolic-rich extracts inhibit key-enzymes linked to type 2 diabetes ( $\alpha$-amylase and $\alpha$-glucosidase) and hypertension (angiotensin I converting enzyme) in vitro. Exp Toxicol Pathol. (2013) 65:3059. doi: 10.1016/j.etp.2011.09.005

10. Ibrahim MA, Koorbanally NA, Islam MS. Antioxidative activity and inhibition of key enzymes linked to type-2 diabetes ( $\alpha$-glucosidase and $\alpha$ amylase) by Khaya Senegalensis. Acta Pharmaceutica. (2014) 64:311-24. doi: 10.2478/acph-2014-0025

11. Striegel L, Kang B, Pilkenton SJ, Rychlik M, Apostolidis E. Effect of black tea and black tea pomace polyphenols on $\alpha$-glucosidase and $\alpha$-amylase the findings in the present study. The present finding would be useful for future research directions on the application of traditional medicinal plants in the development of nutraceuticals and pharmaceuticals.

\section{AUTHOR CONTRIBUTIONS}

SS-L conducted all the experiments, data analyzing and writing the first draft of the manuscript. HR, the principal investigator, contributed by advising methods and experimental design, supervising data analysis and reviewing the manuscript.

\section{ACKNOWLEDGMENTS}

The authors kindly acknowledge the financial support provided by the Engage Grant of the Natural Sciences and Engineering Research Council (NSERC) of Canada and assistant given to collect plant materials by Kier Knudsen of the Dark Tickle Company, St. Lunaire-Griquet, NL, Canada.

inhibition, relevant to type 2 diabetes prevention. Front Nutr. (2015) 2:3. doi: $10.3389 /$ fnut.2015.00003

12. Buchholz T, Melzig MF. Medicinal plants traditionally used for treatment of obesity and diabetes mellitus - screening for pancreatic lipase and $\alpha$-amylase inhibition. Phytother Res. (2016) 30:260-6. doi: 10.1002/ptr.5525

13. Rupasinghe HPV, Balasuriya N, Wang Y. Prevention of type 2 diabetes by polyphenols of fruits. In: Kaïs H, Al-Gubory KH, Laher I, editors. Nutritional Antioxidant Therapies: Treatments and Perspectives. Springer (2017) 447-66. doi: 10.1007/978-3-319-67625-8_17

14. Patel DK, Kumar R, Laloo D, Hemalatha S. Diabetes mellitus: an overview on its pharmacological aspects and reported medicinal plants having antidiabetic activity. Asian Pac J Trop Biomed. (2012) 2:411-20. doi: 10.1016/S2221-1691(12)60067-7

15. Kim DH, Lee S, Chung YW, Kim BM, Kim H, Kim K, et al. Antiobesity and antidiabetes effects of a cudrania tricuspidata hydrophilic extract presenting PTP1B inhibitory potential. Biomed Res Int. (2016) 2016:8432759. doi: $10.1155 / 2016 / 8432759$

16. Nistor Baldea LA, Martineau LC, Benhaddou-Andaloussi A, Arnason JT, Lévy É, Haddad PS. Inhibition of intestinal glucose absorption by anti-diabetic medicinal plants derived from the James Bay Cree traditional pharmacopeia. J Ethnopharmacol. (2010) 132:473-82. doi: 10.1016/j.jep.2010.07.055

17. Parmar I, Rupasinghe H. Antioxidant capacity and anti-diabetic activity of wild berry stem infusions. Euro J Med Plants. (2015) 8:11-28. doi: 10.9734/EJMP/2015/17115

18. Jçdrejek D, Kontek B, Lis B, Stochmal A, Olas B. Evaluation of antioxidant activity of phenolic fractions from the leaves and petals of dandelion in human plasma treated with $\mathrm{H} 2 \mathrm{O} 2$ and $\mathrm{H} 2 \mathrm{O} 2 / \mathrm{Fe}$. Chem Biol Interact. (2017) 262:29-37. doi: 10.1016/j.cbi.2016.12.003

19. Sekhon-Loodu S, Warnakulasuriya SN, Rupasinghe HPV, Shahidi F. Antioxidant ability of fractionated apple peel phenolics to inhibit fish oil oxidation. Food Chem. (2013) 140:189-96. doi: 10.1016/j.foodchem.2013.02.040

20. SingletonVL, Orthofer RL-RR. Analysis of total phenols and other oxidation substrates and antioxidant by means of Folin Ciocalteu reagent. Meth. Enzymol. (1999) 299:153-78. doi: 10.1016/S0076-6879(99)99017-1

21. Benzie IFF, Strain JJ. The ferric reducing ability of plasma (FRAP) as a measure of "antioxidant power": the FRAP assay. Anal Biochem. (1996) 239:70-6. doi: 10.1006/abio.1996.0292

22. Shimada K, Fujikawa K, Yahara K, Nakamurat T. Antioxidative properties of xanthan on the autoxidation of soybean oil in cyclodextrin emulsion. J Agricult Food Chem. (1992) 40:945-8. doi: 10.1021/jf00018a005 
23. Sudha P, Zinjarde SS, Bhargava SY, Kumar AR. Potent $\alpha$-amylase inhibitory activity of Indian ayurvedic medicinal plants. BMC Complement Altern Med. (2011) 11:5. doi: 10.1186/1472-6882-11-5

24. Li D-Q, Qian Z-M, Li S-P. Inhibition of three selected beverage extracts on $\alpha$-glucosidase and rapid identification of their active compounds using HPLC-DAD-MS/MS and biochemical detection. J Agric Food Chem. (2010) 58:6608-13. doi: 10.1021/jf100853c

25. Brownlee M, Vlassara H, Kooney A, Ulrich P, Cerami A. Aminoguanidine prevents diabetes-induced arterial wall protein cross-linking. Science. (1986) 232:1629-32. doi: 10.1126/science.3487117

26. Riss TL, Moravec RA. Use of multiple assay endpoints to investigate the effects of incubation time, dose of toxin, and plating density in cell-based cytotoxicity assays. Assay Drug Dev Technol. (2004) 2:51-62. doi: $10.1089 / 154065804322966315$

27. Hyun TK, Kim H-C, Ko Y-J, Kim J-S. Antioxidant, $\alpha$-glucosidase inhibitory and anti-inflammatory effects of aerial parts extract from Korean crowberry (Empetrum nigrum var. Japonicum). Saudi J Biol Sci. (2016) 23:181-8. doi: $10.1016 /$ j.sjbs.2015.02.008

28. Kelly GS. Rhodiola rosea: a possible plant adaptogen. Alternat. Med. Rev. A J Clin Ther. (2001) 6:293-302. Available online at: http://nutradvance.pt/wpcontent/uploads/2016/04/Ref84.293.pdf

29. Nakata M, Myoda T, Wakita Y, Sato T, Tanahashi I, Toeda K, et al. Volatile components of essential oil from cultivated Myrica gale var. Tomentosa and its antioxidant and antimicrobial activities. J Oleo Sci. (2013) 62:755-62. doi: $10.5650 /$ jos. 62.755

30. Wang H, Liu T, Huang D. Starch hydrolase inhibitors from edible plants. Adv Food Nutr Res. (2013) 70:103-36. doi: 10.1016/B978-0-12-416555-7.00 003-5

31. Schütz K, Kammerer DR, Carle R, Schieber A. Characterization of phenolic acids and flavonoids in dandelion (Taraxacum officinale WEB. ex WIGG) root and herb by high-performance liquid chromatography/electrospray ionization mass spectrometry. Rapid Commu Mass Spectrom. (2005) 19:17986. doi: $10.1002 / \mathrm{rcm} .1767$

32. Choi U-K, Lee O-H, Yim JH, Cho C-W, Rhee YK, Lim S-I, et al. Hypolipidemic and antioxidant effects of dandelion (Taraxacum officinale) root and leaf on cholesterol-fed rabbits. Int J Mol Sci. (2010) 11:67-78. doi: $10.3390 /$ ijms 11010067
33. Cimino S, Sortino G, Favilla V, Castelli T, Madonia M, Sansalone S, et al. Polyphenols: KEY issues involved in chemoprevention of prostate cancer. Oxid Med Cell Longev. (2012) 2012:632959. doi: 10.1155/2012/632959

34. Rupasinghe HPV, Boehm M, Sekhon-Loodu S, Parmar I, Bors B, Jamieson A. Anti-inflammatory activity of haskap cultivars is polyphenols-dependent. Biomolecules. (2015) 5:1079-98. doi: 10.3390/biom5021079

35. Oboh G, Puntel RL, Rocha JBT. Hot pepper (Capsicum annuum, Tepin and Capsicum chinese, Habanero) prevents Fe2+-induced lipid peroxidation in brain - in vitro. Food Chem. (2007) 102:178-85. doi: 10.1016/j.foodchem.2006.05.048

36. Wu CH, Yen GC. Inhibitory effect of naturally occurring flavonoids on the formation of advanced glycation endproducts. J Agric Food Chem. (2005) 53:3167-73. doi: 10.1021/jf048550u

37. Kowalska K, Olejnik A, Rychlik J, Grajek W. Cranberries (Oxycoccus quadripetalus) inhibit adipogenesis and lipogenesis in 3T3-L1 cells. Food Chem. (2014) 148:246-52. doi: 10.1016/j.foodchem.2013.10.032

38. Shobha CR, Prashant V, Akila P, Chandini R, Suma MN, Basavanagowdappa H. Fifty percent ethanolic extract of Momordica charantia inhibits adipogenesis and promotes adipolysis in 3T3-L1 pre-adipocyte cells. Rep Biochem Mol Biol. (2017) 6:22-32.

39. Tansey JT, Sztalryd C, Gruia-Gray J, Roush DL, Zee JV, Gavrilova O, et al. Perilipin ablation results in a lean mouse with aberrant adipocyte lipolysis, enhanced leptin production, and resistance to diet-induced obesity. Proc Natl Acad Sci. (2001) 98:6494-9. doi: 10.1073/pnas.1010 42998

Conflict of Interest Statement: The authors declare that the research was conducted in the absence of any commercial or financial relationships that could be construed as a potential conflict of interest.

Copyright (๑) 2019 Sekhon-Loodu and Rupasinghe. This is an open-access article distributed under the terms of the Creative Commons Attribution License (CC BY). The use, distribution or reproduction in other forums is permitted, provided the original author(s) and the copyright owner(s) are credited and that the original publication in this journal is cited, in accordance with accepted academic practice. No use, distribution or reproduction is permitted which does not comply with these terms. 